\title{
Improvement of Porous GaAs (100) Structure through Electrochemical Etching Based on DMF Solution
}

\author{
Muhamad Ikram Md Taib, Norzaini Zainal, and Zainuriah Hassan \\ Nano-Optoelectronics Research and Technology Laboratory, School of Physics, Universiti Sains Malaysia, 11800 Penang, Malaysia \\ Correspondence should be addressed to Norzaini Zainal; norzaini@usm.my
}

Received 15 April 2014; Accepted 16 June 2014; Published 30 June 2014

Academic Editor: Anukorn Phuruangrat

Copyright (c) 2014 Muhamad Ikram Md Taib et al. This is an open access article distributed under the Creative Commons Attribution License, which permits unrestricted use, distribution, and reproduction in any medium, provided the original work is properly cited.

\begin{abstract}
We report on the fabrication of porous $\mathrm{GaAs}(100)$ using three different acids, $\mathrm{H}_{2} \mathrm{SO}_{4}$, $\mathrm{HF}$, and $\mathrm{HCl}$, diluted in DMF based solutions. The mixture of $\mathrm{H}_{2} \mathrm{SO}_{4}$ with DMF showed the best porous structures in comparison to other acids. The concentration of the DMF solution was then varied for a fixed concentration of $\mathrm{H}_{2} \mathrm{SO}_{4}$. It was apparent that the different concentration of the DMF solvent gave different types of morphology of the porous GaAs. Furthermore, a higher current density improved the uniformity of the pores distribution. The best porous GaAs exhibited well-defined circular shaped pores with high uniformity. To the best of our knowledge, such structure produced in such manner has never been reported so far. Finally, the optimum etching conditions of the pores were proposed.
\end{abstract}

\section{Introduction}

Porous GaAs has been identified as a potential substrate for promoting low threading dislocations and strain for overgrown epitaxial layer [1]. Producing porous GaAs in a well-defined structure with high pore distribution density is quite challenging. However, with rapid advancements in fabrication technology nowadays, it is possible to achieve high quality porous GaAs structure in a much simple and low cost manner. One possible way is to use electrochemical etching techniques with a proper electrolyte solution. So far, sulphuric acid $\left(\mathrm{H}_{2} \mathrm{SO}_{4}\right)[2,3]$, hydrochloric acid $(\mathrm{HCl})[4,5]$, and hydrofluoric acid (HF) [6-8] have been used as the acid in the mixed solution for etching GaAs substrate. However, the quality of the reported porous GaAs is still far from perfection and it is not compatible to be used in subsequent growth for device fabrication.

We are aware that the choice of electrolyte solution is an essential factor for success etching processes and subsequently improving the structure of the pores. Note that improper electrolyte solution generally results in high oxidation that would limit the etching process. Dimethylformamide (DMF) is an organic solvent that is able to suppress the electrochemical oxidation of silicon ( $\mathrm{Si}$ ) [9]. In fact, such organic solvent has been widely used for achieving macroporous structure in p-type Si. Quite recently, Ghoshal et al. [10] has reported that the use of DMF has allowed a uniform distribution of macroporous of $\mathrm{p}$-Si template useful for biosensing application. In addition, DMF offers a reasonable control on the pores dimension. If this technology were applied to GaAs, a number of novel innovations and applications can be explored further.

In this work, we investigate the optimum etching conditions for (100)-oriented GaAs. A number of GaAs samples were etched using different acids (which were mixed in DMF based solution), different concentration of DMF, and different applied current density. The etching process is performed by electrochemical etching technique as mentioned above. The effect of using different etching parameters on the morphological and structural properties of the porous GaAs samples was investigated. Finally, the optimum etching conditions for the best porous GaAs are proposed.

\section{Materials and Methods}

In this work, a number of bulk n-type GaAs (100) samples with the resistivity of $1.1-1.9 \times 10^{-3} \Omega \cdot \mathrm{cm}$ and thickness 
TABLE 1: Details of the etching parameters for the porous GaAs samples.

\begin{tabular}{lcc}
\hline Sample group & Etching solution & ${\mathrm{Current} \mathrm{density,} J\left(\mathrm{~mA} / \mathrm{cm}^{2}\right)}^{2}$ \\
\hline A & $\mathrm{HF}: \mathrm{DMF}(1: 3)$ & 25 \\
B & $\mathrm{HCl}: \mathrm{DMF}(1: 3)$ & 25 \\
C & $\mathrm{H}_{2} \mathrm{SO}_{4}: \mathrm{DMF}(1: 3)$ & 25 \\
D & $\mathrm{H}_{2} \mathrm{SO}_{4}: \mathrm{DMF}(1: 1)$ & 250 \\
E & $\mathrm{H}_{2} \mathrm{SO}_{4}: \mathrm{DMF}(1: 3)$ & 250 \\
F & $\mathrm{H}_{2} \mathrm{SO}_{4}: \mathrm{DMF}(1: 9)$ & 250 \\
$\mathrm{G}$ & $\mathrm{H}_{2} \mathrm{SO}_{4}: \mathrm{DMF}(1: 3)$ & 350 \\
$\mathrm{H}$ & $\mathrm{H}_{2} \mathrm{SO}_{4}: \mathrm{DMF}(1: 3)$ with improved current conductivity & 250 \\
\hline
\end{tabular}

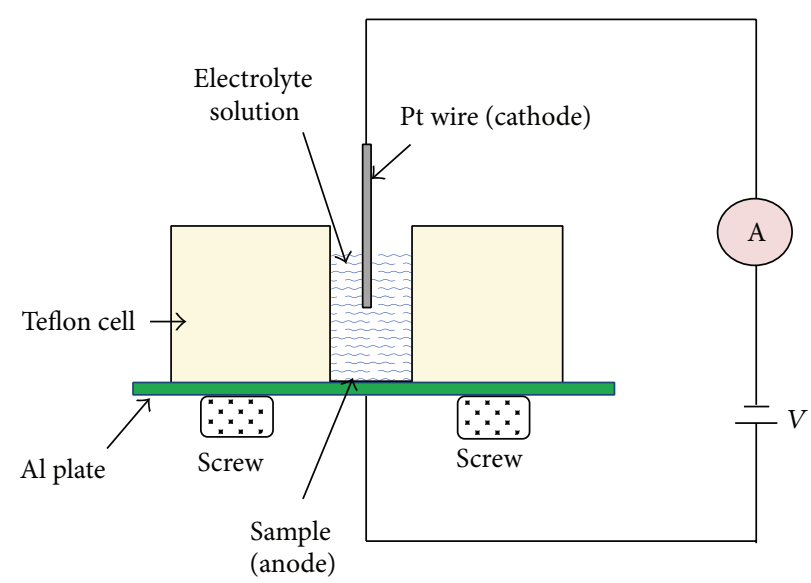

Figure 1: Schematic diagram of electrochemical etching experiment for producing porous GaAs.

of $325-375 \mu \mathrm{m}$ were used for making the porous structures. The electrochemical etching experiment was set up as shown in Figure 1. The current density was varied between 25 and $350 \mathrm{~mA} / \mathrm{cm}^{2}$. All the samples were etched within $t=$ 10 minutes. Prior to the etching process, the samples were cleaned in two stages: (1) dipped in $\mathrm{H}_{2} \mathrm{SO}_{4}: \mathrm{H}_{2} \mathrm{O}_{2}: \mathrm{H}_{2} \mathrm{O}$ bath for $30 \mathrm{~s}$ and rinsed by deionized water for $5 \mathrm{~min}$ and (2) cleaned in $\mathrm{HCL}: \mathrm{H}_{2} \mathrm{O}(1: 1)$ solution for 2 min to remove the oxide film and subsequently rinsed by deionized water for $5 \mathrm{~min}$. In this experiment, the optimal type of acid, DMF concentration, and applied current density will be identified so that the best porous GaAs structure can be expected. This has been done by characterizing the porous GaAs samples under field emission scanning electron microscopy (FESEM) with the magnification of 50,000x while the surface roughness was measured by atomic force microscopy (AFM) using tapping mode in a scan area of $10 \mu \mathrm{m} \times 10 \mu \mathrm{m}$. On the other hand, to determine the crystalline quality of each sample, X-ray diffraction (XRD) measurement by means of (002) rocking curve was carried out. The XRD measurement used $\mathrm{Cu}-\mathrm{K} \alpha 1$ as the radiation source with $\lambda=1.5406 \AA$. Details of etching parameters are summarized in Table 1.

\section{Results and Discussions}

3.1. Identify the Optimum Acid. Figure 2 shows the surface images of porous GaAs etched with different etching solutions. It can be seen that the mixed solutions of HF : DMF and $\mathrm{HCl}: \mathrm{DMF}$ do not show promising results compared to $\mathrm{H}_{2} \mathrm{SO}_{4}$ : DMF of the porous GaAs structure. Detailed justification of this behaviour is not well understood but we suspect that the anion charge from $\mathrm{H}_{2} \mathrm{SO}_{4}$ may play a role. It is reasonable to suggest that GaAs bonding was being attacked more by $\mathrm{SO}_{4}{ }^{2-}$ ion than $\mathrm{F}^{-}$and $\mathrm{Cl}^{-}$ions because the $\mathrm{SO}_{4}{ }^{2-}$ ion has two extra electrons, which helps to promote more etching activity. In addition to that, $\mathrm{H}_{2} \mathrm{SO}_{4}$ has stronger acidity compared to the other two acids due to high concentration of $\mathrm{H}^{+}$ions and this might have enhanced the etching process.

3.2. Identify the Optimum DMF Concentration. In the subsequent experiment, the current density was increased up to $250 \mathrm{~mA} / \mathrm{cm}^{2}$ as a means to improve the porous structure of the GaAs samples. At this stage, the GaAs samples were etched at different concentration of DMF and the results are shown in Figure 3. It is clearly seen that all the samples exhibit mesoporous-like structures on the surfaces. The overall reaction that occurred during the electrochemical etching could be expressed as follows:

$$
\begin{aligned}
2 \mathrm{GaAs}+ & \left(\mathrm{CH}_{3}\right)_{2} \mathrm{NC}(\mathrm{O}) \mathrm{H}+3 \mathrm{H}_{2} \mathrm{SO}_{4} \\
\longrightarrow & \left(\mathrm{CH}_{3}\right)_{2} \mathrm{NH}+\mathrm{COH}_{2}+\mathrm{Ga}\left(\mathrm{SO}_{4}\right)_{3} \\
& +\mathrm{As}_{2}(\mathrm{~g})+2 \mathrm{H}_{2}(\mathrm{~g})
\end{aligned}
$$




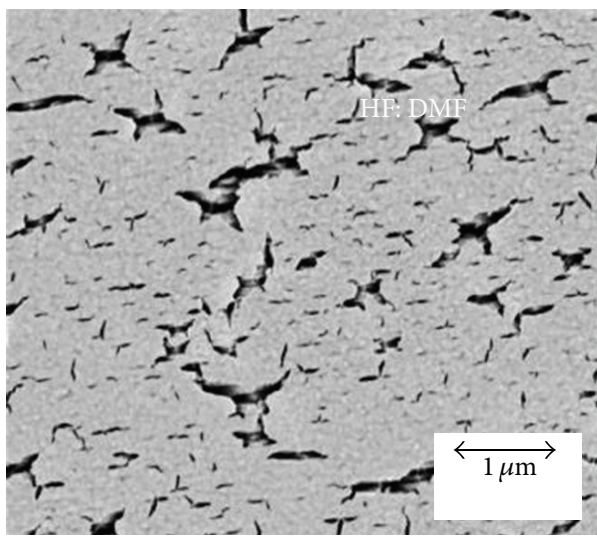

(a)

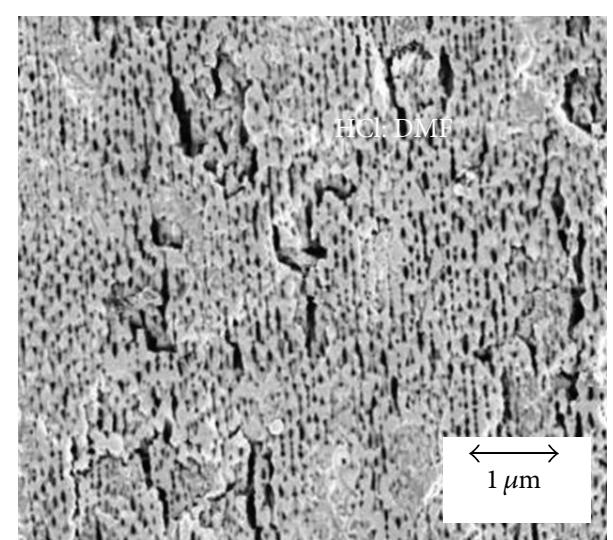

(b)

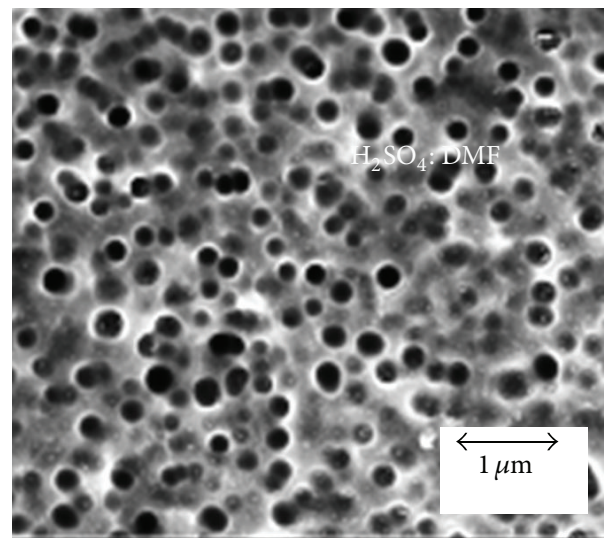

(c)

Figure 2: Surface morphology of porous GaAs etched with different types of etching solution for (a) sample A, (b) sample B, and (c) sample $\mathrm{C}$, at current density, $J=\sim 25 \mathrm{~mA} / \mathrm{cm}^{2}$, and time, $t=10 \mathrm{~min}$.

Figure 3(a) shows that the porous GaAs etched in $\mathrm{H}_{2} \mathrm{SO}_{4}$ :DMF solution with ratio of $1: 1$. The porous structure starts to form; however, this particular solution is not strong enough to promote deeper pores. When the ratio of DMF was increased, there is significant change in the uniformity and pore sizes. Under this condition, the etching process enhances creating more and deeper pores. Hence, more dissolution will occur with higher concentration of DMF to promote uniformed pore distributions on the surface. However, when the concentration of DMF is giving a further increased, no more significant changes are observed. This may be due to the fact that higher concentration of DMF would lead to higher $\mathrm{H}$-passivation that gradually reduces the conductivity and dielectric constant of the electrolyte, therefore, slowing down the etching process [9]. It is worth highlighting that our porous GaAs samples are having well-defined circular shaped pores with high uniform distribution on the surface. Such structure has never been reported so far.

Next, the roughness of the porous GaAs samples was determined using AFM measurements. Figure 4 shows the morphology of the porous GaAs samples. The result of the bulk GaAs is included for comparison. The root mean square (rms) values for the bulk, sample $\mathrm{D}$, sample E, and sample $\mathrm{F}$ are $2.3 \mathrm{~nm}, 112.0 \mathrm{~nm}, 52.8 \mathrm{~nm}$, and $36.7 \mathrm{~nm}$, respectively. Apparently, the bulk sample has the lowest roughness than the porous sample and this is expected since the etching process would typically cause roughness on the surface. Note that, the surface roughness of the porous GaAs decreases as the DMF ratio increases. This result may relate to the smaller remaining GaAs nanocrystals on the surface (please refer to Figure 3(c)). In this measurement, we also measured the depth of porous GaAs samples. The average depths of porous GaAs for samples D, E, and F are $400 \mathrm{~nm}, 500 \mathrm{~nm}$, and $200 \mathrm{~nm}$, respectively. These results imply that the $\mathrm{H}$ passivation starts to occur when the concentration composition of DMF is beyond the optimum level.

The structural quality of the porous GaAs samples was determined using the full width half maximum (FWHM) of XRD rocking curve (002). The result is shown in Figure 5. In general, the FWHM of the porous GaAs are larger than the bulk GaAs. Such behaviour is also typically observed in porous $\mathrm{GaN}$ [11]. This arises from the formation of nonstoichiometric Ga- or As-rich surface, incorporation of impurity, or surface defects during etching. However, among the porous GaAs sample, it is shown that the porous GaAs 


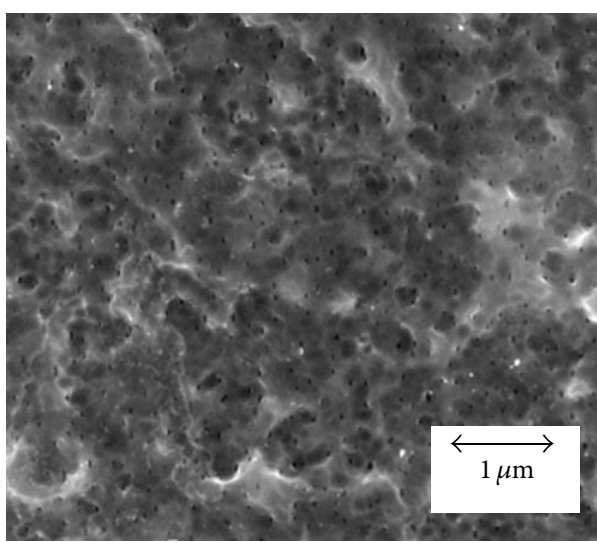

(a) $1: 1$

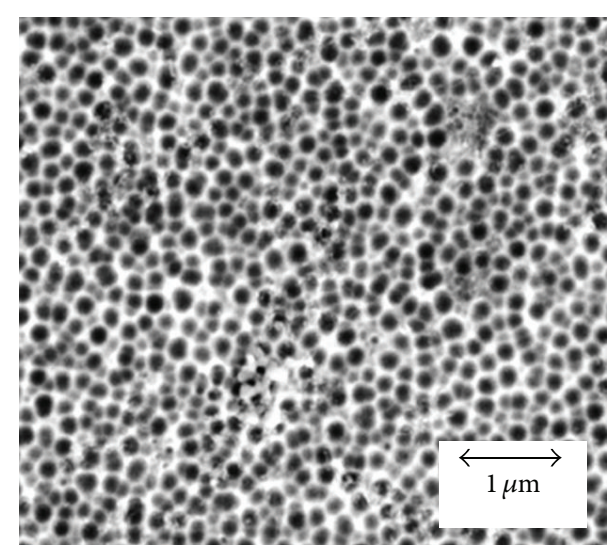

(b) $1: 3$

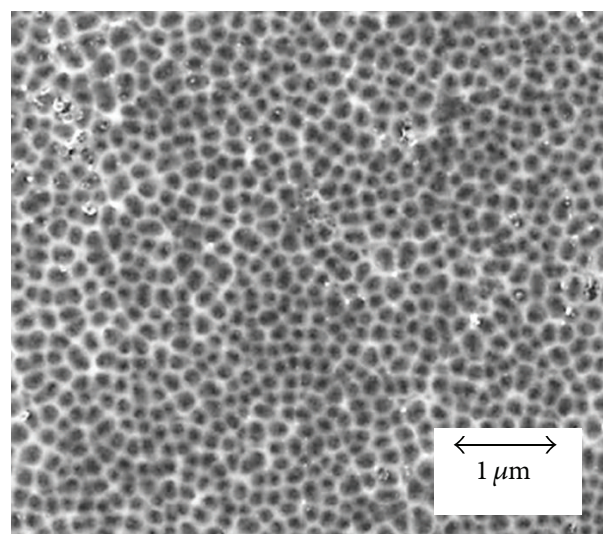

(c) $1: 9$

FIGURE 3: Surface morphology of porous GaAs with the variation of DMF concentration in the mixture of $\mathrm{H}_{2} \mathrm{SO}_{4}$ acid for (a) sample D, (b) sample E, and (c) sample F, at current density, $J=\sim 250 \mathrm{~mA} / \mathrm{cm}^{2}$, and time, $t=10 \mathrm{~min}$.

with $\mathrm{DMF}: \mathrm{H}_{2} \mathrm{SO}_{4}$ ratio of $1: 3$ has the lowest value, indicating that this solution is the optimum electrolyte parameter for the porous GaAs.

3.3. Identify the Optimum Current Density. The effect of using different applied current density on the surface morphology of porous GaAs was further investigated. Figure 6 shows the images of porous GaAs with different current density. Clearly, a uniform distribution of pores is obtained with current density of $250 \mathrm{~mA} / \mathrm{cm}^{2}$ compared to a lower current density of $25 \mathrm{~mA} / \mathrm{cm}^{2}$. As expected, higher current will inject more holes towards the surface and, subsequently, more pores will be formed. Further increase in the current density causes more surface damages and roughness. Besides, no significant improvement was observed. To further increase the conductivity, the contacts between the GaAs sample and the Al plate were improved by introducing a thin Al-film. The result is shown in Figure 6(d). Obviously, a uniform shape of pores is expected. Such technique helps to improve the current conductivity during the etching process. The rocking curve (RC) from (002) XRD measurement of the sample shows a smaller FWHM $\left(0.019^{\circ}\right)$. This value is almost comparable to the bulk sample. Such porous GaAs sample is suitable to be used as a template/substrate for the overgrown epitaxy as well as being beneficial to be adopted in advanced fabrication of nanostructures.

\section{Conclusions}

To conclude, the etching solution of $\mathrm{H}_{2} \mathrm{SO}_{4}$ : DMF with the ratio of $1: 3$ under $250 \mathrm{~mA} / \mathrm{cm}^{2}$ promotes better morphological properties of porous GaAs. In addition to that, an increase in current conductivity shows better formation of the porous GaAs structures. We propose that the best porous GaAs shown in our work has great potential to be used in advanced semiconductor epitaxy and nanostructure technologies.

\section{Conflict of Interests}

The authors declare that there is no conflict of interests regarding the publication of this paper.

\section{Acknowledgments}

This work was supported by the Research University Individual 2012 under Grant account no. 1001/PFIZIK/811231, The World Academy of Sciences (TWAS) research Grant (reference 11-122RG/MSN/AS_C; UNESCO FR: 3240262661), 
RMS: $2.3 \mathrm{~nm}$

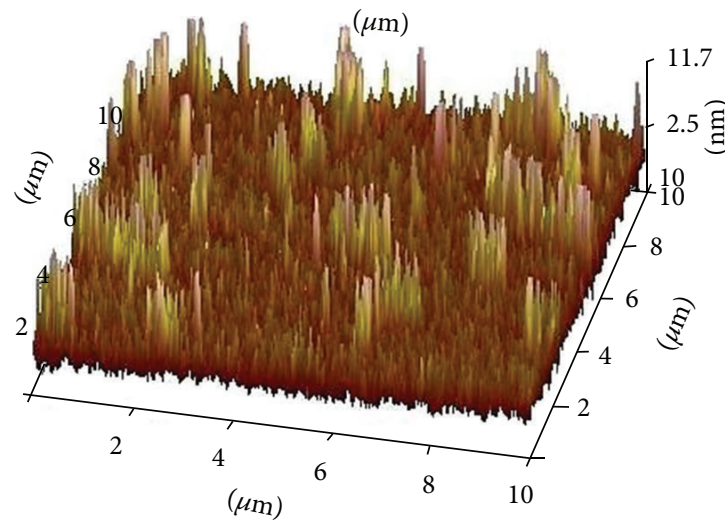

(a)

RMS: $52.8 \mathrm{~nm}$

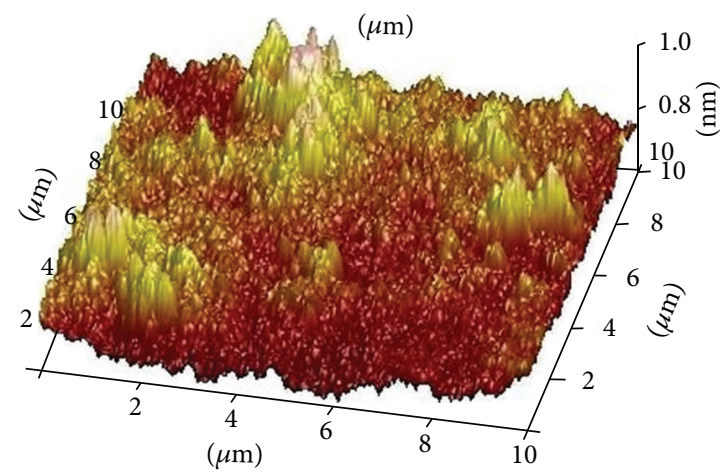

(c)
RMS: $112.0 \mathrm{~nm}$

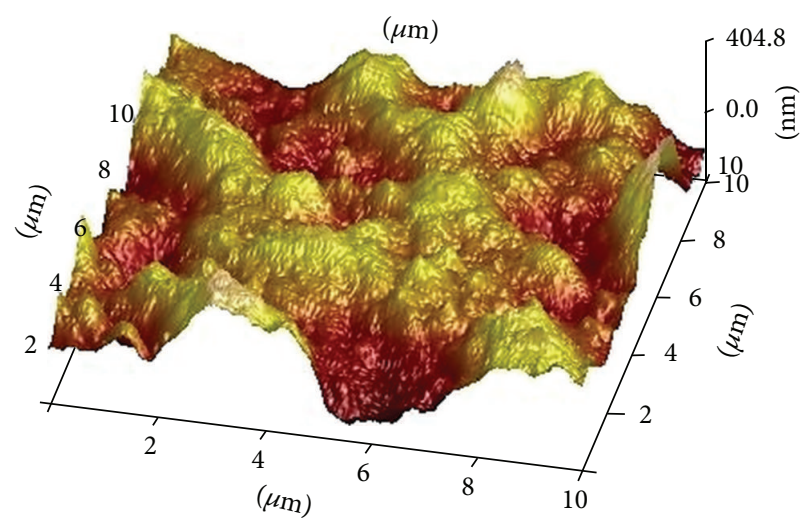

(b)

RMS: $36.7 \mathrm{~nm}$

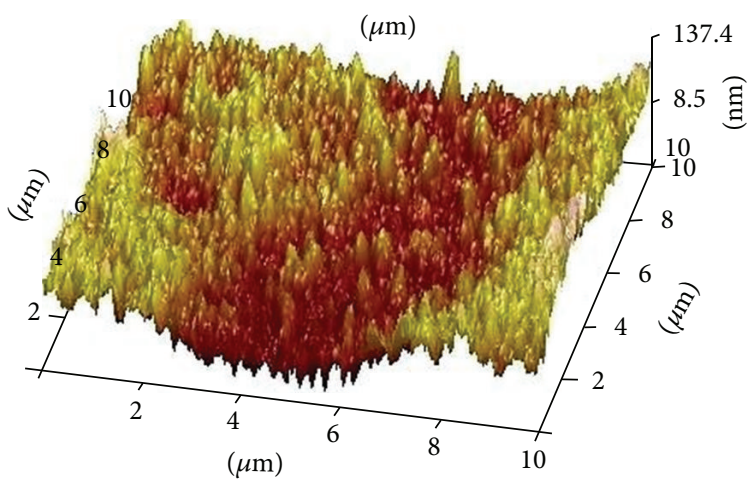

(d)

FIGURE 4: AFM images of 3D surface morphology of bulk and porous $\mathrm{GaAs}$ with the variation of $\mathrm{DMF}$ concentration in the mixture of $\mathrm{H}_{2} \mathrm{SO}_{4}$ acid for (a) bulk, (b) sample D, (c) sample E, and (d) sample F, at current density, $J=\sim 250 \mathrm{~mA} / \mathrm{cm}^{2}$, and time, $t=10 \mathrm{~min}$.

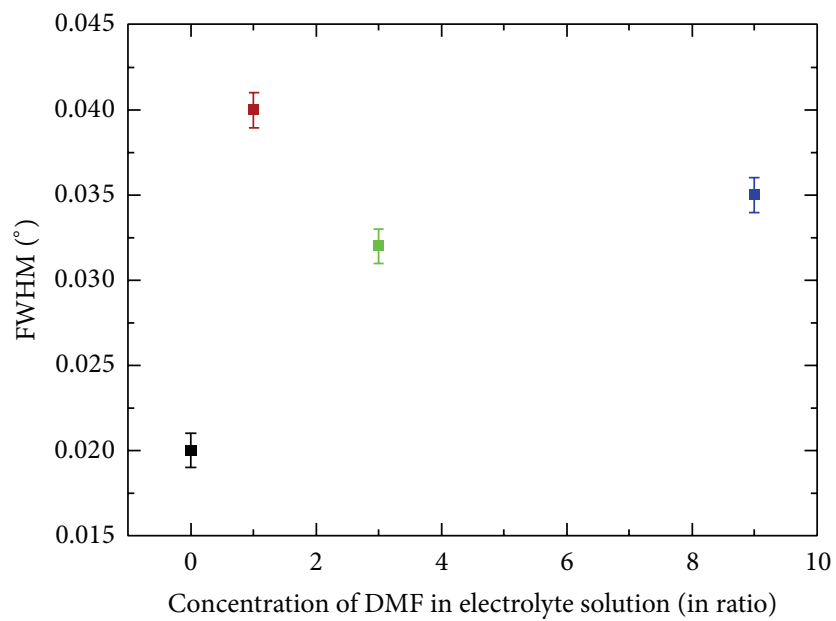

FIGURE 5: FWHM versus DMF composition (in ratio) taken from (002) XRD rocking curve measurement. 


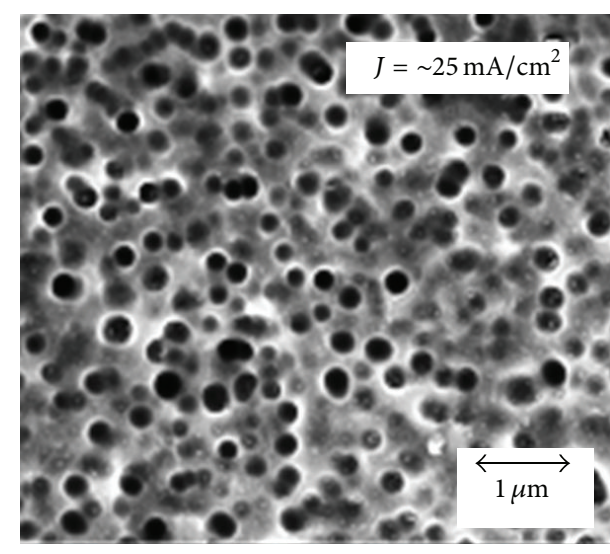

(a)

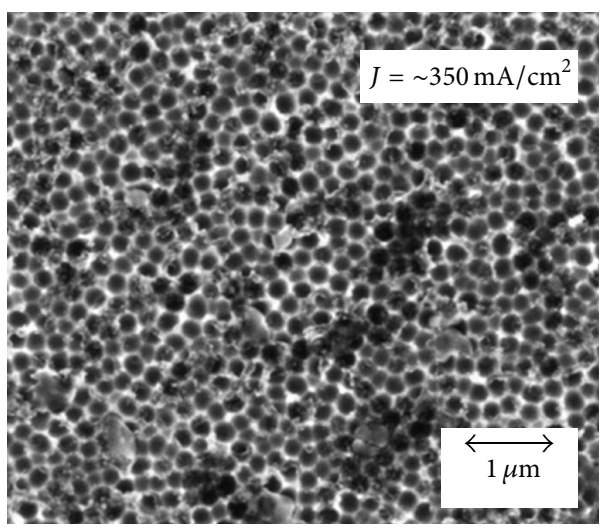

(c)

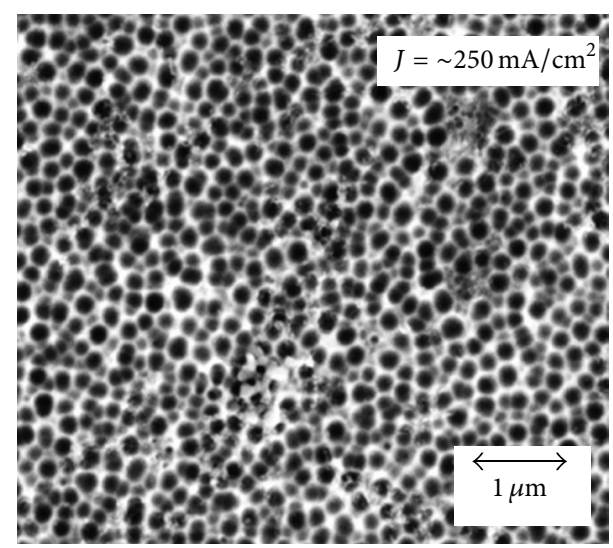

(b)

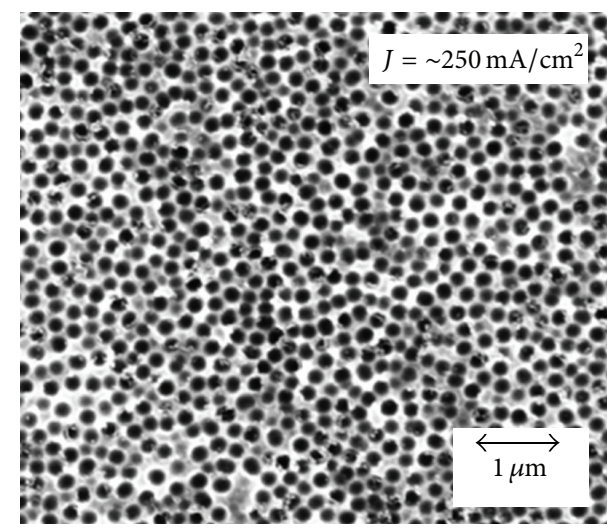

(d)

FiguRE 6: Surface morphology of porous GaAs with variation of current density of (a) $25 \mathrm{~mA} / \mathrm{cm}^{2}$ (sample C), (b) $250 \mathrm{~mA} / \mathrm{cm}^{2}$ (sample E), (c) $350 \mathrm{~mA} / \mathrm{cm}^{2}$ (sample G), and (d) $250 \mathrm{~mA} / \mathrm{cm}^{2}$ with improvement in current conductivity (sample $\mathrm{H}$ ), at etching time, $t=10 \mathrm{~min}$.

and the Exploratory Research Grant Scheme under Grant account no. 203/PFIZIK/6730095. The authors would like to thank W. Maryam for the fruitful discussion and English editing and the NOR Lab staff for technical support.

\section{References}

[1] V. V. Kidalov, G. A. Sukach, A. O. Petukhov, A. S. Revenko, and E. P. Potapenko, "Photoluminescent and structural properties of GaN thin films obtained by radical-beam gettering epitaxy on porous GaAs (0 0 1)," Journal of Luminescence, vol. 102-103, pp. 712-714, 2003.

[2] I. M. Tiginyanu, G. Irmer, J. Monecke, A. Vogt, and H. L. Hartnagel, "Porosity-induced modification of the phonon spectrum of n-GaAs," Semiconductor Science and Technology, vol. 12, no. 4, pp. 491-493, 1997.

[3] S. Langa, J. Carstensen, M. Christophersen et al., "Uniform and nonuniform nucleation of pores during the anodization of $\mathrm{Si}$, Ge, and III-V semiconductors," Journal of the Electrochemical Society, vol. 152, no. 8, pp. C525-C531, 2005.

[4] M. Naddaf and S. Saloum, "Nanostructuring-induced modification of optical properties of p-GaAs (1 0 0)," Physica E: LowDimensional Systems and Nanostructures, vol. 41, no. 10, pp. 1784-1788, 2009.
[5] P. Schmuki, L. E. Erikson, D. J. Lockwood, J. W. Fraser, G. Champion, and H. J. Labbé, "Formation of visible light emitting porous GaAs micropatterns," Applied Physics Letters, vol. 72, no. 9, 1998.

[6] M. Naddaf and M. Saad, "Novel optical and structural properties of porous GaAs formed by anodic etching of $\mathrm{n}^{+}-\mathrm{GaAs}$ in a HF: $\mathrm{C}_{2} \mathrm{H}_{5} \mathrm{OH}: \mathrm{HCl}: \mathrm{H}_{2} \mathrm{O}_{2}: \mathrm{H}_{2} \mathrm{O}$ electrolyte: effect of etching time," Journal of Materials Science: Materials in Electronics, vol. 24, no. 7, pp. 2254-2263, 2013.

[7] J. Grym, D. Nohavica, P. Gladkov, E. Hulicius, J. Pangrác, and K. Piksová, "Epitaxial growth on porous GaAs substrates," Comptes Rendus Chimie, vol. 16, no. 1, pp. 59-64, 2013.

[8] V. V. Kidalov, G. A. Sukach, A. S. Revenko, and A. D. Bayda, "Properties of cubic GaN films obtained by nitridation of porous GaAs(001)," Physica Status Solidi (A) Applications and Materials Science, vol. 202, no. 8, pp. 1668-1672, 2005.

[9] H. Föll, M. Christophersen, J. Carstensen, and G. Hasse, "Formation and application of porous silicon," Materials Science and Engineering R, vol. 39, no. 4, pp. 93-141, 2002.

[10] S. Ghoshal, A. A. Ansar, S. O. Raja et al., "Superparamagnetic iron oxide nanoparticle attachment on array of micro test tubes and microbeakers formed on p-type silicon substrate for biosensor applications," Nanoscale Research Letters, vol. 6, article 540, 2011. 
[11] A. P. Vajpeyi, S. J. Chua, S. Tripathy et al., "High optical quality nanoporous GaN prepared by photoelectrochemical etching," Electrochemical and Solid-State Letters, vol. 8, no. 4, pp. G85G88, 2005. 

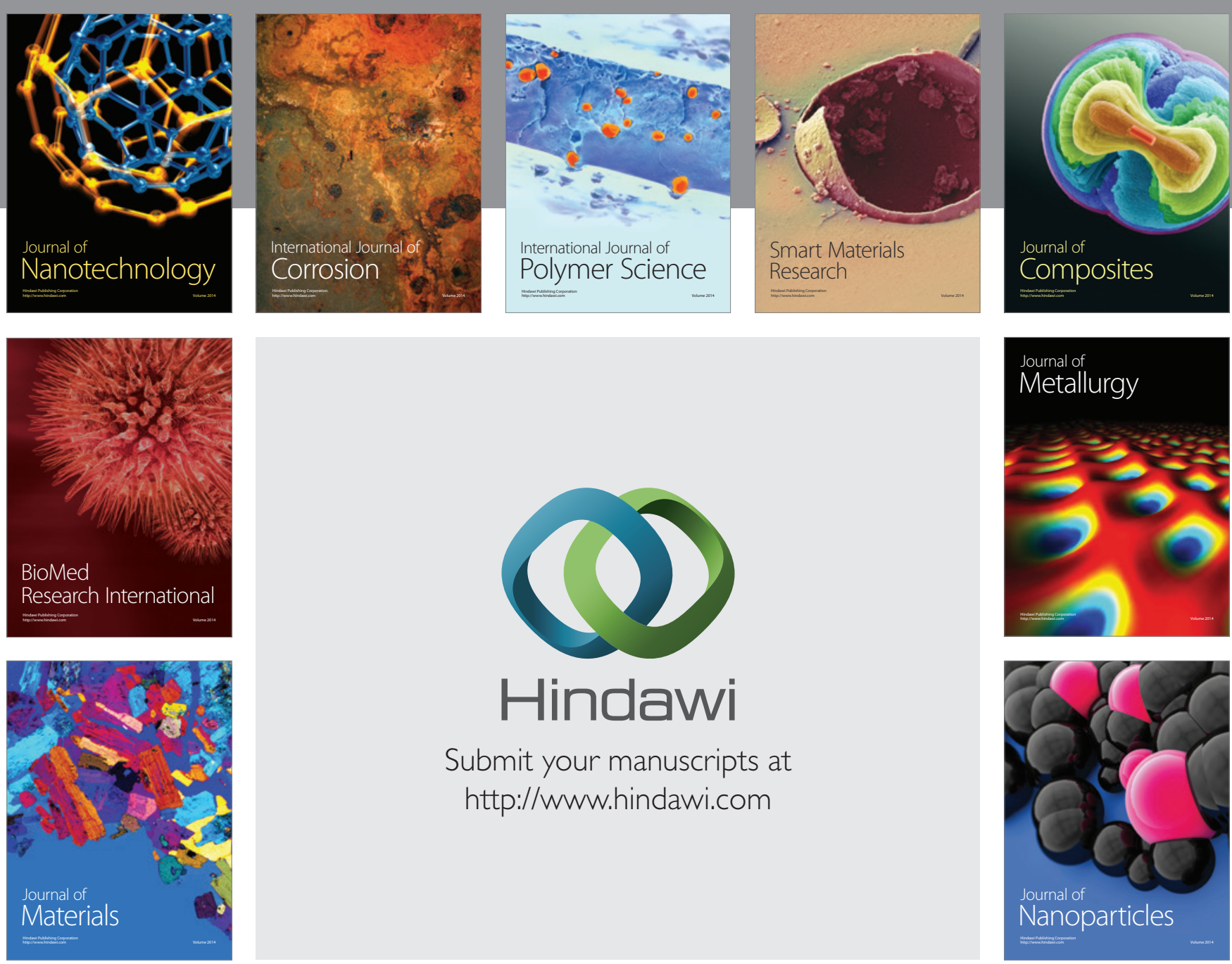

Submit your manuscripts at http://www.hindawi.com
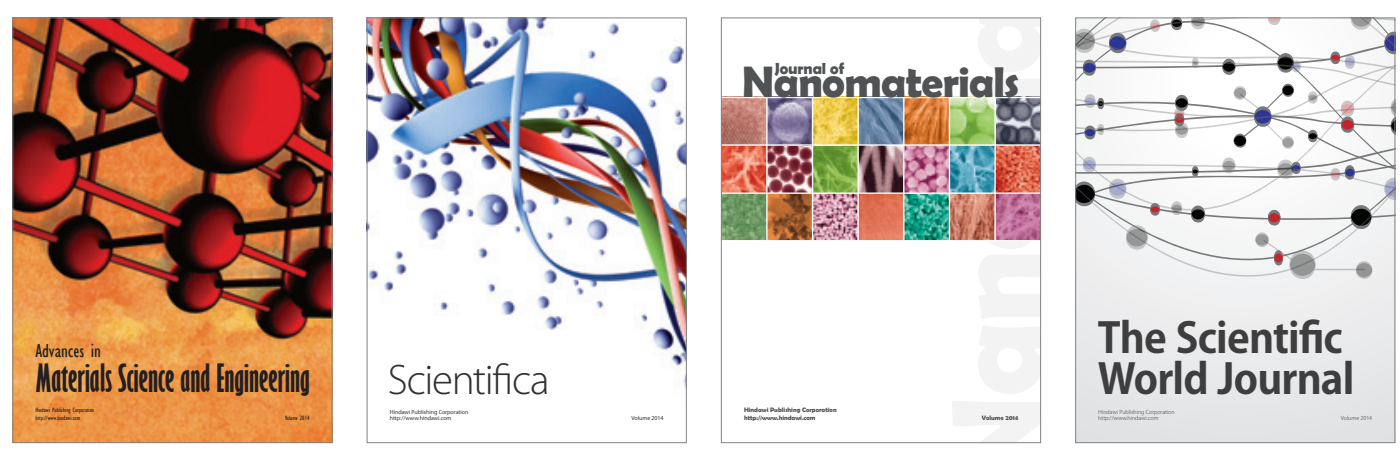

\section{The Scientific World Journal}
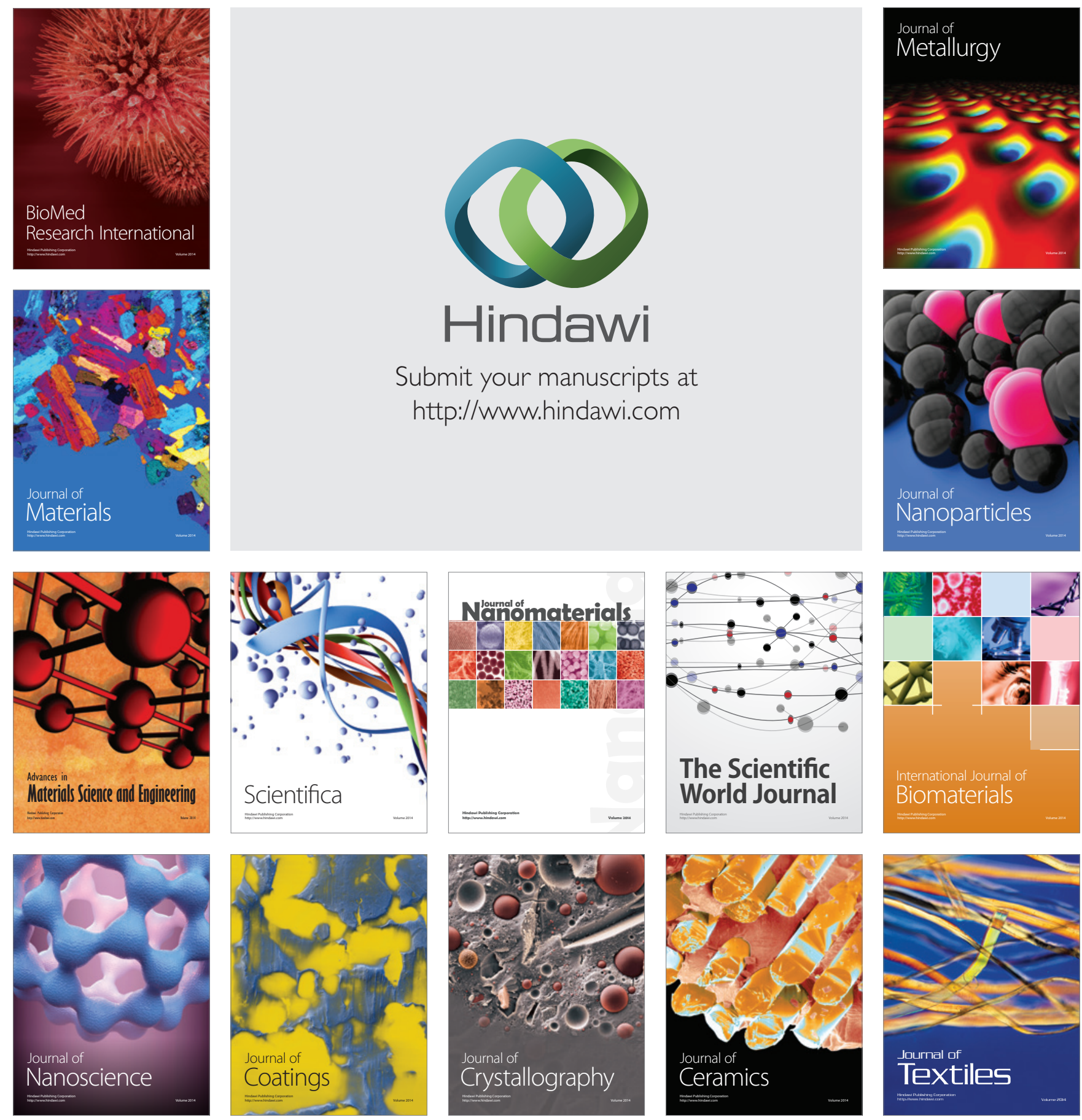